\title{
Frequencies of Specific Antibody-Producing Gells for Sheep Red Blood Cells and for Phosphorylcholine in Human Tonsillar B Lymphocytes Transformed by Epstein-Barr Virus
}

\author{
Osamu Yoshie and Yasushi Ono \\ Department of Bacteriology, Tohoku University School of \\ Medicine, Sendai 980
}

\begin{abstract}
Yoshie, O. and Ono, Y. Frequencies of Specific Antibody-Producing Cells for Sheep Red Blood Cells and for Phosphorylcholine in Human Tonsillar B Lymphocytes Transformed by Epstein-Barr Virus. Tohoku J. exp. Med., 1982, 137 (3), 233-244 - The frequencies of transformed B cells and of transformed specific antibody-producing cells in human tonsillar lymphocytes infected with Epstein-Barr virus (EBV) were determined by limiting dilution analyses. The latter was corrected by the former and the frequencies of specific antibodyproducing cells in EBV-transformed B cell populations were obtained. The frequencies of specific B cells for sheep red blood cells were calculated to be one in 500 to 2,000 EBV-transformed tonsillar B cells obtained from four donors, while those of specific B cells for a hapten, phosphorylcholine, were one in 700 to 5,000 . The method may be useful to define the repertoire of specificities in the human B cell populations. - human B cells; antibody repertoire; polyclonal transformation; Epstein-Barr virus
\end{abstract}

Human B cells have receptors for Epstein-Barr virus (EBV) (Jondal and Klein 1973; Einhorn et al. 1978). Infection of human lymphocytes with certain strains of EBV readily induces transformation of B cells into continuously growing lymphoblastoid cells which possess surface immunoglobulins (Ig) and produce secretory Ig (Katsuki and Hinuma 1975; Yoshie et al. 1980). EBV-induced lymphoblastoid cell lines are usually polyclonal in origin and contain various specific antibody-producing cells at least in the early stages of growth (Rosen et al. 1977; Kirchner et al. 1979; Tsuchiya et al. 1980). It has been suggested that EBV may preferentially transform B cells with surface IgM and thus establish B cell lines producing IgM (Katsuki et al. 1977; Steel et al. 1977; Yoshie et al. 1980), but B cells which are committed to produce other isotypes of Ig can be transformed by EBV (Yoshie et al. 1980). The transformation of human B cells by EBV has

Received for publication, October 13, 1981.

Abbreviations used in this paper: EBV, Epstein-Barr virus; SRBC, sheep red blood cells; PC, phosphorylcholine; OHRBC, human type O red blood cells; UCBL umbilical cord blood lymphocytes; Ig, immunoglobulin; MMC, mitomycin C; PHA, passive hemagglutination. 
been used to establish human cell lines producing antibodies with known specificities (Steinitz et al. 1977, 1979a, b; Zurawski et al. 1978; Kozbor et al. 1979; Tsuchiya et al. 1980; Yoshie and Ono 1980).

In the previous study we showed that polyclonal transformation of human B cells by EBV was useful for the quantitative examination of various specific B cells in human lymphocyte populations by a limiting dilution analysis (Yoshie et al. 1981). In the present study we further developed the system and determined the frequencies of specific B cells in EBV-transformed human B cell populations.

\section{Materials and Methods}

Chemicals. PC was purchased from Sigma Chemical Co., St. Louis, Mo., USA. The calcium ions were precipitated with phosphate before use. Methyliodide was purchased from E. Merck, Darmstadt, West Germany, p-diazonium phenylphosphorylcholine (DPPC) was prepared according to the procedure of Chesebro and Metzgar (1972) and stored at $-80^{\circ} \mathrm{C}$ until use. All other chemicals were of analytical grade, commercially available.

PC-erythrocyte conjugate. PC-coupled human type $\mathrm{O}$ red blood cells (PC-OHRBC) were prepared as described previously (Yoshie and Ono 1980).

Preparation of human lymphocytes. Human tonsillar lymphocytes were prepared and frozen-stored at $-80^{\circ} \mathrm{C}$ as described previously (Yoshie et al. 1980). The cell populations contained more than $95 \%$ lymphocytes. The staining of surface Ig was performed as described previously (Yoshie et al. 1980). The mean \pm s.D. of the frequencies of surface Ig positive cells in the tonsillar lymphocytes used in the present study was $33 \pm 11 \%$. Umbilical cord blood lymphocytes were prepared as described previously (Yoshie et al. 1980). Umbilical cord blood lymphocytes were suspended in culture medium at a cell concentration of $5 \times 10^{6} / \mathrm{ml}$ and treated with $25 \mu \mathrm{g} / \mathrm{ml}$ of mitomycin C (MMC) (Kyowa Hakko Kogyo, Tokyo) at $37^{\circ} \mathrm{C}$ for $30 \mathrm{~min}$. The cells were washed three times, resuspended in culture medium at a cell concentration of $2 \times 10^{6} / \mathrm{ml}$ and used as feeder cells (MMCtreated UCBL).

Virus. The cell line B95-8 (Miller and Lipman 1973) was used as the source of EBV. The preparation of the culture supernatant of B95-8 cells and the determination of virus titer by UCBL transformation assay were performed as described previously (Yoshie et al. 1980). The titer of the virus stock used in the present study was $10^{5.0} 50 \%$ transformation doses (TD50)/ml.

Virus infection. The frozen-stored tonsillar lymphocytes were thawed rapidly at $41^{\circ} \mathrm{C}$ and washed three times in culture medium (RPMI-1640 supplemented with $20 \%$ fetal calf serum and antibiotics). Viable cells were counted in $0.1 \%$ trypan blue in PBS (viability usually about $80 \%$ ) and suspended in the culture medium at a cell concentration of $1 \times 10^{7} /$ ml. To this cell suspension, EBV suspension was added. The following formula was used to express the multiplicity of infection (m.o.i.):

$$
\begin{aligned}
& \mathrm{EBV}(\mathrm{ml}) \times 10^{5.0}(\mathrm{TD} 50) / \mathrm{ml} \\
& \text { Cell suspension }(\mathrm{ml}) \times 10^{7} / \mathrm{ml}
\end{aligned}
$$

The mixture was incubated at $37^{\circ} \mathrm{C}$ for $2 \mathrm{hr}$ with occasional gentle agitation. The cells were then washed three times and resuspended in the culture medium at a cell concentration of $1 \times 10^{6} / \mathrm{ml}$.

Determination of the number of transformed cells. The numbers of transformed cells in EBV-infected tonsillar lymphocytes were determined by a limiting dilution analysis. Serially diluted EBV-infected cells were distributed in $0.01 \mathrm{ml}$ volume in Falcon 3034 microtest plates (1,000 to 4 cells/well, 36 wells for each number of the cells cultured). $2 \times 10^{4}$ MMC-treated UCBL were added in $0.01 \mathrm{ml}$ volume to each culture as feeder cells $\left(1 \times 10^{5} / \mathrm{ml}\right)$. The plates were incubated at $37^{\circ} \mathrm{C}$ in a well humidified $5 \% \mathrm{CO}_{2}$ atmosphere 
and half the medium was changed every three to four days. Transformation as revealed by active proliferation of lymphoblastoid cells was determined in each culture under the microscope after three weeks. It was confirmed that MMC-treated UCBL infected with EBV did not undergo transformation.

Determination of the number of transformed specific antibody-producing cells. The numbers of specific antibody-producing cells transformed in EBV-infected tonsillar lymphocytes were also determined by a limiting dilution analysis. Serially diluted EBVinfected cells were distributed in $0.1 \mathrm{ml}$ volume in Falcon 3040 plates $\left(1 \times 10^{4}\right.$ to $3 \times 10^{4}$ cells/culture, 60 cultures for each number of cells). $2 \times 10^{5}$ MMC-treated UCBL were added in $0.1 \mathrm{ml}$ volume to each culture as feeder cells $\left(1 \times 10^{6} / \mathrm{ml}\right)$. The plates were incubated at $37^{\circ} \mathrm{C}$ and half the medium was changed every three to four days. After two weeks when growth of transformed lymphoblastoid cells in each culture reached the maximum level, the culture supernatants were individually harvested and specific antibody activities in the culture supernatants were determined.

Assays for anti-SRBC and anti-PC antibodies in the culture supernatants. Anti-SRBC and anti-PC antibodies in the culture supernatants were detected by hemolysis and passive hemagglutination (PHA), respectively, as described previously (Yoshie and Ono 1980; Yoshie et al. 1981). The titers of the specific antibody activities ranged between $2^{2}$ and $2^{7}$ to $2^{8}$.

Clonal transformation in semi-solid agarose and detection of anti-SRBC antibody-producing colonies. Clonal transformation of EBV-infected tonsillar lymphocytes in semi-solid agarose was performed as described previously (Yoshie et al. 1980). Colonies producing anti-SRBC antibodies were detected as follows: $0.5 \mathrm{ml}$ of $0.7 \%$ agarose in MEM containing $0.25 \%$ SRBC was overlayed on the developing colonies and solidified at $4^{\circ} \mathrm{C} .1 \mathrm{ml}$ of fresh guinea pig serum diluted 1:20 with MEM was then overlayed as complement and the cultures were incubated at $37^{\circ} \mathrm{C}$ for 2 to $3 \mathrm{hr}$. Hemolytic plaques with a colony at the center were detected and counted.

\section{Results}

\section{Transformation frequencies of EBV-infected tonsillar lymphocytes}

A limiting dilution analysis was performed to determine the number of cells which actually underwent transformation in EBV-infected tonsillar lymphocytes. It was observed that at the numbers of $\mathrm{EBV}$-infected cells in which the numbers of cells which underwent transformation were presumably limiting, only fractions of the cultures showed transformation, i.e., active proliferation of lymphoblastoid cells (Fig. 1). The logarithms of the fractions of non-transformed cultures (negative
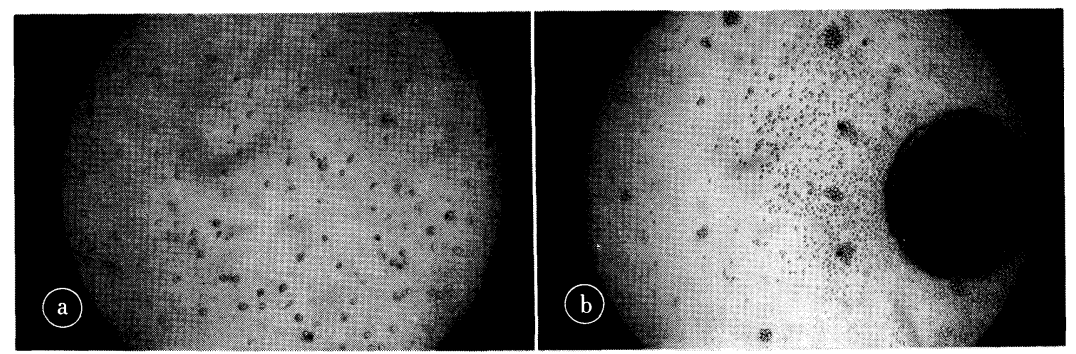

Fig. 1. The appearances of transformed and non-transformed cultures at three weeks after EBV-infection. Serially diluted EBV-infected tonsillar lymphocytes were cultured with $2 \times 10^{4}$ MMC-treated UCBL in $0.02 \mathrm{ml}$ volume in microtest plates. After three weeks of culture, cell growth in each culture was determined under the microscope. A: A non-tranformed culture in which only small number of large adherent cells remained. B: A tranformed culture in which lymphoblastoid cells were growing in a large cell cluster. 
fractions) were then plotted against the numbers of EBV-infected cells seeded per culture. As shown in Fig. 2, linear relationships corresponding to one hit type of Poisson's distribution were obtained. The results indicated that only cells which

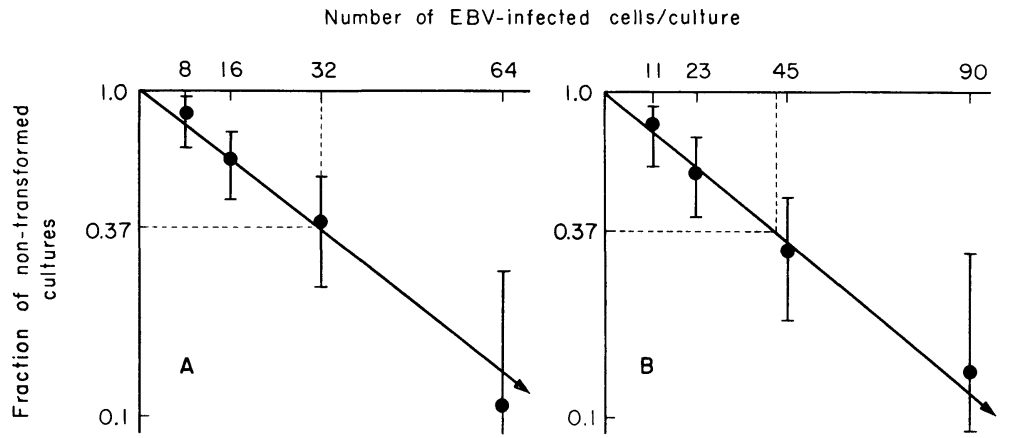

Fig. 2. Limiting dilution analysis of EBV-infected tonsillar lymphocytes for the determination of transformation frequency. Serially diluted EBV-infected cells were cultured with $2 \times 10^{4}$ MMC-treated UCBL in $0.02 \mathrm{ml}$ volume in microtest plates (36 cultures for each number of EBV-infected cells tested). EBV-infection was done at an m.o.i. of 0.1 (see Materials and Methods). After three weeks of culture, active proliferation of lymphoblastoid cells in each culture was determined (see Fig. 1). The dotted lines point to the numbers of EBV-infected cells cultured with which $37 \%$ of all cultures did not show transformation. Vertical bars represent $98 \%$ confidence limits. Tonsillar lymphocytes were obtained from (A) T.S. 6 years, and (B) W.G., 12 years.

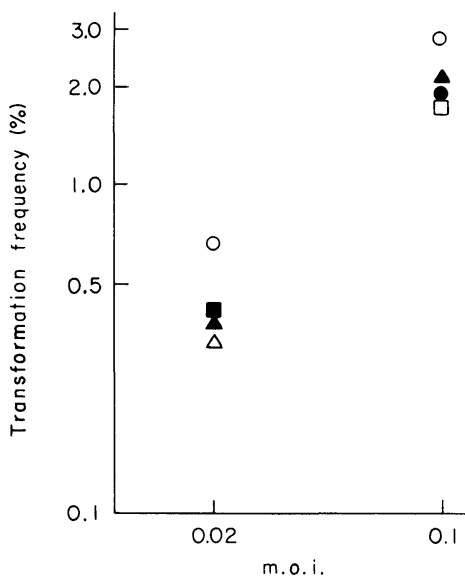

Fig. 3. Transformation frequencies of EBV-infected tonsillar lymphocytes derived from six donors. Transformation frequencies of EBV-infected cells were determined by limiting dilution analysis as described in Fig. 2. Each symbol denotes the mean of two separate determinations with each donor. O, T.S., 6 years, $0.65 \pm 0.07$ (s.D.)\% at an m.o.i. of 0.02 and $2.8 \pm 0.21 \%$ at an m.o.i. of $0.1 ; \Delta$, T.M., 9 years, $0.33 \pm 0.17 \%$ at an m.o.i. of 0.02 ; 口, H.T., 11 years, $1.8 \pm 0 \%$ at an m.o.i. of 0.1 ; $\bullet$, W.G., 12 years, $0.38 \pm 0.03 \%$ at an m.o.i. of 0.02 and $1.9 \pm 0.57 \%$ at an m.o.i. of 0.1 ; $\Delta$, U.T., 12 years, $2.1 \pm 0.28 \%$ at an m.o.i. of 0.1 ; a, T.E., 13 years, $0.39 \pm 0.01 \%$ at an m.o.i. of 0.02 . s.D, standard deviation. 
underwent transformation were limiting in these cultures. According to one hit type of Poisson's distribution the numbers of EBV-infected cells which contained the average of one transformed cell could be obtained from Fig. 2 as those numbers at which $37 \%$ of the cultures was non-transformed. Transformation frequency was then expressed as the percentage of cells transformed in total EBV-infected lymphocytes $(3.1 \%$ and $2.3 \%$ for Figs. $2 \mathrm{~A}$ and $2 \mathrm{~B}$, respectively).

Fig. 3 shows the transformation frequencies of tonsillar lymphocytes from six donors infected with EBV at an m.o.i. of 0.02 and/or 0.1 (see Materials and Methods). EBV-infected cells from different donors showed nearly similar transformation frequencies. This indicated that tonsillar lymphocytes from donors with similar ages showed similar levels of susceptibility to transformation by EBV. Fig. 3 also shows that transformation frequencies were proportional to EBV-doses. This suggested a simple one-hit type relationship between tonsillar B cells and EBV.

Frequencies of anti-SRBC or anti-PC antibody-producing cells transformed by $E B V$

The determination of the numbers of anti-SRBC or anti-PC antibody-producing cells transformed in EBV-infected cells was also performed by a limiting dilution analysis. The culture supernatants obtained after two weeks of culture were assayed for these specific antibody activities. The logarithms of fractions of cultures which did not contain specific antibody activities (negative fractions) were then plotted against the numbers of EBV-infected cells cultured. As shown in Fig. 4, the negative fractions again followed one hit type of Poisson's distribution. This indicated that only specific antibody-producing cells transformed by EBV were limiting in these cultures and the assays used could detect specific antibody

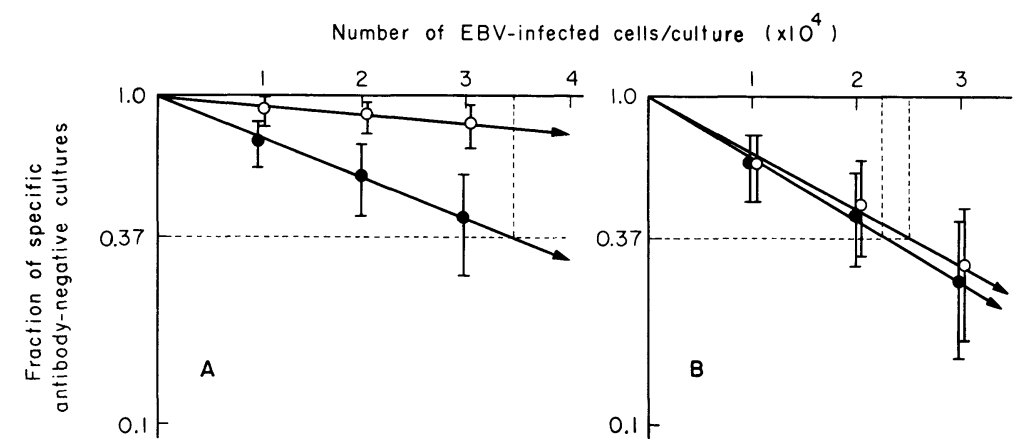

Fig. 4. Limiting dilution analysis of EBV-infected tonsillar lymphocytes for determination of the frequencies of transformed specific B cells in total EBV-infected cells. $1 \times 10^{4}$ to $3 \times 10^{4} \mathrm{EBV}$-infected cells were cultured with $2 \times 10^{6} \mathrm{MMC}$-treated UCBL in $0.2 \mathrm{ml}$ volume in microtest plates. EBV-infection was done at an m.o.i. of 0.1. After two weeks of culture, anti-SRBC and anti-PC antibody activities in the culture supernatants were detected by hemolysis and PHA, respectively. Each point was based on 60 cultures. The dotted lines point to the numbers of EBV-infected cells cultured with which $37 \%$ of all cultures did not show the specific antibody activities. Vertical bars represent $98 \%$ confidence limits. Tonsillar lymphocytes were obtained from (A) T.S., 6 years, and (B) W.C., 12 years. •, anti-SRBC antibodies; O, anti-PC antibodies. 
TABLE 1. Frequencies of anti-SRBC and anti-PC antibody producing cells in EBVtransformed tonsillar B lymphocytes determined by limiting dilution analyses

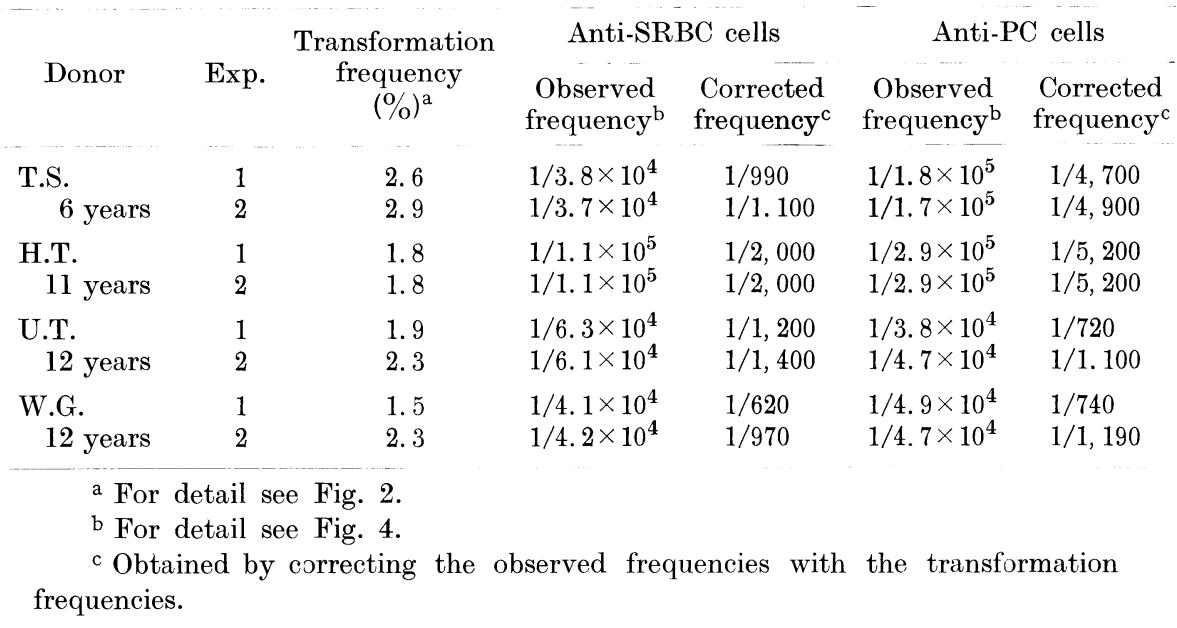

activities derived from a single clone of transformed specific B cells. From one hit type of Poisson's distribution the numbers of EBV-infected cells which contained the average of one specific $B$ cell which underwent transformation were obtained from Fig. 4 as the numbers of cells at which $37 \%$ of the cultures did not contain specific antibody activities.

The numbers of EBV-infected cells which contained the average of one specific $\mathrm{B}$ cell which underwent transformation were then corrected by the transformation frequencies of EBV-infected cells determined on the same feeder cells and the frequencies of specific B cells in EBV-transformed B cell populations were obtained. Table 1 shows the frequencies of anti-SRBC or anti-PC specific B cells in the EBVtransformed tonsillar B cell populations derived from four donors thus determined. The transformation frequencies and the frequencies of specific B cells obtained were reproducible in separate experiments with each donor. It was shown that comparatively large numbers of $\mathrm{B}$ cells were specific for $\mathrm{SRBC}$ or $\mathrm{PC}$, i.e., one in 500 to 2,000 EBV-transformed B cells for SRBC and one in 700 to 5,000 EBV-transformed B cells for PC.

\section{Randomness of transformation of EBV-infected cells}

In order to see whether transformation by EBV was random among EBVinfected tonsillar B cells with or without particular specificities, the transformation frequencies of total $\mathrm{EBV}$-infected cells and the frequencies of transformed specific B cells were determined with tonsillar lymphocytes infected with various doses of EBV. As shown in Fig. 5, the transformation frequencies of total EBVinfected cells and the numbers of specific B cells transformed in $1 \times 10^{4} \mathrm{EBV}$-infected cells increased in parallel with increasing doses of EBV and reached plateau levels at about the same doses of EBV. The results showed that the transformation frequencies of the total B cells and the specific B cells were similar in the wide 

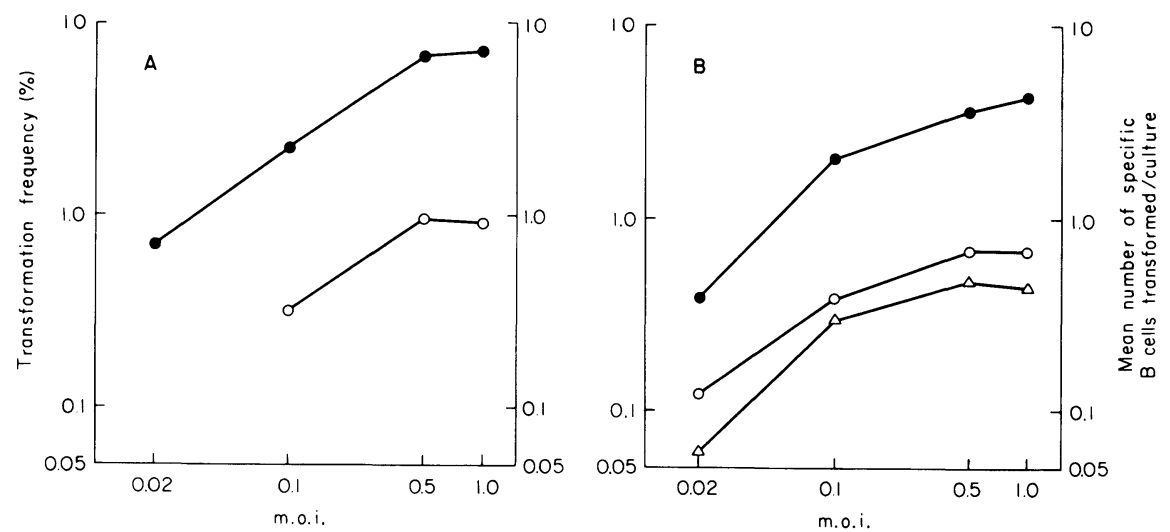

Fig. 5. Parallel increases of the transformation frequency of total EBV-infected cells and the average number of specific $B$ cells transformed per $1 \times 10^{4}$ EBV-infected cells with increasing doses of EBV. Tonsillar lymphocytes were infected with EBV at various m.o.i. and the determinations of the transformation frequency and the frequency of transformed specific B cells in $1 \times 10^{4} \mathrm{EBV}$-infected cells were performed as described in Figs. 2 and 4 . The average numbers of specific B cells transformed in $1 \times 10^{4} \mathrm{EBV}$-infected cells (total 60 cultures) were directly calculated from the fractions of cultures which did not show specific antibody activity $(F n)$ using the formula of Poisson's distribution: $F n=e^{-\mathrm{m}}$. A: T.S., 6 years. B: W.G., 12 years, $\bullet$, transformation frequency; $\mathrm{O}$, anti-SRBC antibodies; $\Delta$, anti-PC antibodies.

range of EBV doses and thus supported the random nature of transformation of tonsillar B cells by EBV.

\section{Clonal transformation and detection of colonies producing anti-SRBC antibodies}

To test further the reliability of the frequencies of specific B cells in EBVtransformed $\mathrm{B}$ cell populations determined by limiting dilution analyses of EBVinfected cells, the frequencies of anti-SRBC antibody producing cells in EBVtransformed $\mathrm{B}$ cell populations were directly determined by seeding $\mathrm{EBV}$-infected tonsillar lymphocytes in semi-solid agarose to induce each transformed cell to grow separately and form a colony and detecting colonies producing anti-SRBC antibodies in situ (Fig. 6). As shown in Table 2, the frequencies of anti-SRBC antibody producing colonies thus determined were quite comparable to the frequencies of anti-SRBC antibody producing cells determined by limiting dilution analyses in separate experiments with different m.o.i. (Exp. 1 and 2, note that the transformation frequencies and the frequencies of colony formation increased nearly proportionally to EBV doses) and with different donors (Exp. 2 and 3). This indicated the reliability of the limiting dilution analyses described in the present study to determine the transformation frequencies of EBV-infected cells and the frequencies of specific B cells in EBV-transformed human B cell populations. 


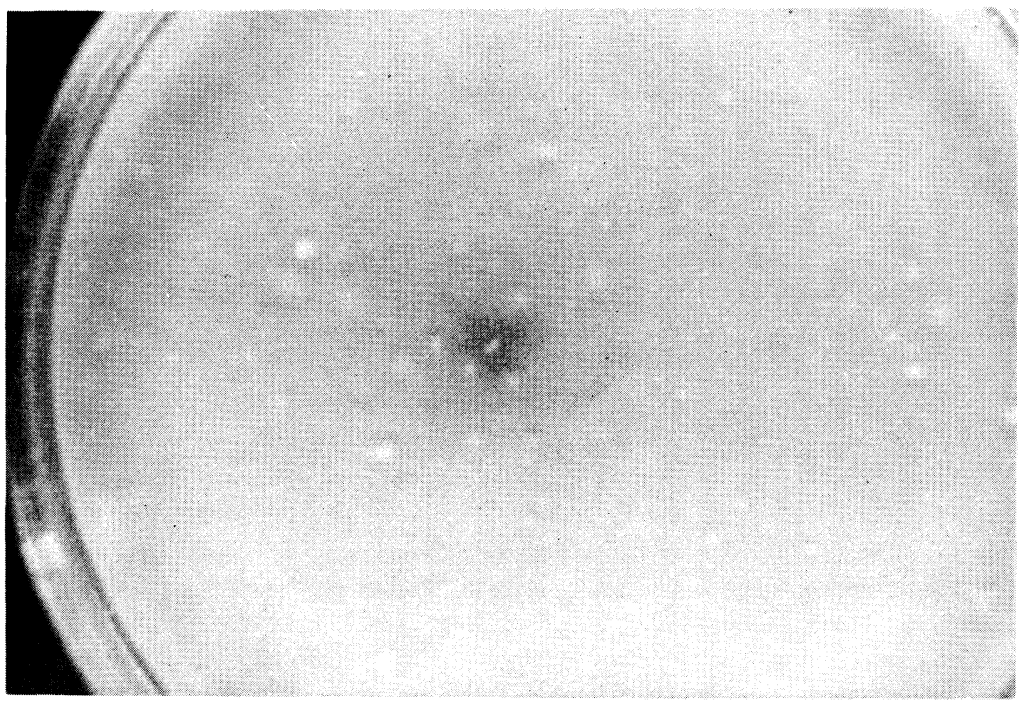

Fig. 6. In situ detection of EBV-transformed clones producing anti-SRBC antibodies. EBV-infected tonsillar lymphocytes were seeded in $0.4 \%$ semi-solid agarose and induced to form monoclonal colonies. After four weeks of culture, colonies producing anti-SRBC antibodies were detected in situ by overlaying $0.7 \%$ agarose containing $0.25 \%$ SRBC and then complement.

TABLE 2. Frequencies of anti-SRBC antibody producing cells in EBV-transformed tonsillar $B$ lymphocytes determined by limiting dilution analyses and clonal transformation

Limiting dilution analyses ${ }^{\mathrm{a}}$

$$
\begin{aligned}
& \text { Exp. Transformation } \\
& \text { frequency }(\%)
\end{aligned}
$$

Corrected
frequency of
anti-SRBC cells
$1 / 740$
$1 / 1,100$
$1 / 520$

Clonal transformation ${ }^{b}$

$\begin{array}{cc}\begin{array}{c}\text { Frequency } \\ \text { of colony } \\ \text { formation }(\%)\end{array} & \begin{array}{c}\text { Frequency } \\ \text { of anti-SRBC } \\ \text { colonies }^{c}\end{array} \\ 0.3 & 1 / 1,020 \\ 0.8 & 1 / 990 \\ 0.8 & 1 / 510\end{array}$

a See Table 1 for detail.

b EBV-infected tonsillar lymphocytes were directly seeded in semi-solid agarose and induced to form monoclonally transformed colonies. More than $10^{4}$ colonies were screened for each determination.

c For detail see Fig. 6. 0.05 .

d Tonsillar lymphocytes from T.S., 6 years, were infected with EBV at an m.o.i. of 0.1 .

e Tonsillar lymphocytes from T.S., 6 years, were infected with EBV at an m.o.i. of

f Tonsillar lymphocytes from W.G., 12 years, were infected with EBV at an m.o.i. of 0.1 .

\section{Discussion}

In view of the polyclonal nature of the transformation of human B cells by EBV (Rosen et al. 1977; Kirchner et al. 1979), the obtained frequencies of specific B cells in EBV-transformed B cell populations may directly reflect the frequencies of 
specific B cells in the original tonsillar B cell populations. There is, however, one critical prerequisite which must be fulfilled for this assumption to be valid, i.e., the randomness of transformation of $\mathrm{B}$ cells by $\mathrm{EBV}$. If all $\mathrm{B}$ cells were randomly transformed by EBV, the determined frequencies of specific B cells in the present study should directly correspond to the frequencies of specific B cells in the original B cell populations. On the other hand, if transformation of B cells by EBV was not at random and there existed subpopulations of B cells each of which had different susceptibilities to transformation by EBV, the determined frequencies of specific B cells might be biased and only indicate the frequencies of these specific B cells in actually transformed B cell populations. Although there are some data which suggest the latter possibility (Katsuki et al. 1977; Steel et al. 1977; Yoshie et al. 1980), these are not yet very conclusive. On the other hand, in the present study we showed that the frequencies of specific B cells for SRBC or PC determined in EBV-transformed B cell populations derived from tonsillar lymphocytes infected with different doses of EBV gave essentially similar values of frequency (Fig. 5 and Table 2). The results, though not conclusive, supported that at least in the early stages of transformation by EBV the induction of growth and Ig production was at random among EBV-infected tonsillar B cells.

In order to bypass the problem of randomness of transformation, one might try to transform essentially all B cells by EBV and to determine the frequencies of specific B cells in such conditions. In the present study, however, we could induce transformation of at most $5 \%$ of the total tonsillar lymphocytes of which about $30 \%$ could be regarded to be B cells because of membrane Ig (Fig. 5 and unpublished data). At present we do not know the reason of the low levels of the maximum transformation frequencies obtained. One reason might be the damages inflicted on the tonsillar lymphocytes by the freeze-store and thaw-recover procedures. The viability of the recovered cells was usually about $80 \%$ and about $50 \%$ of the viable cells rapidly died during the first several days of culture after EBV-infection before steady increase in cell number began (data not shown). Another reason might be that the plating efficiency of EBV-transformed tonsillar B cells on allogeneic MMC-treated UCBL feeder cells was not $100 \%$. In line with these speculations were the results that the maximum transformation frequencies of EBV-infected fresh UCBL determined by the limiting dilution analysis in the presence of syngeneic feeder cells were in good agreement with the frequencies of surface IgM positive cells (in preparation). Of course it might be that not all tonsillar B cells were transformable by EBV. In that case only the frequencies of specific B cells in the subpopulations of tonsillar B cells which were transformable by EBV were determined in the present study. Further studies are necessary to answer these questions.

Andersson et al. (1977) reported the frequencies of B cells producing specific antibodies for two heterologous erythrocytes and two haptens in IgM secreting clones induced by polyclonal activation of mouse splenic B cells with lipopolysaccharide (LPS) and lipoprotein. In their system one-third to one-fourth of mouse 
splenic B cells were reactive to LPS or lipoprotein, so that their analyses of the repertoire of antibody specificities might be restricted to the $\mathrm{B}$ cell subpopulations reactive to these mitogens. It is, however, noteworthy that the frequencies of antiSRBC antibody-producing cells determined in their analysis and in the present study are quite comparable, i.e., one in 1,000 mitogen-reactive splenic B cells and one in 500 to 2,000 EBV-transformed tonsillar B cells. The frequencies of specific B cells obtained by these studies are about 100 -fold higher than those obtained by the previous studies in which the specific B cells were stimulated by antigens and rather show close proximity to the frequencies of antigen-binding cells (for review see Sigal and Klinman 1978). This may not be unexpected, however, because B cells which can bind antigens but cannot be stimulated by them because of low antigenbinding affinities can be induced to produce their antibodies in the systems of polyclonal B cell activation. The systems of polyclonal B cell activation, therefore, bypassing the antigen-dependent activation of specific B cells, may offer unique opportunities to induce a total repertoire of antibodies that an organism can make. These systems may be valuable to determine not only the frequencies of clones with particular specificities but also those of clones with particular idiotypic markers as reported by Eichman et al. (1977) and to define the entire diversity of Ig genes by isoelectric focusing analysis.

Human donors are genetically heterogenous and have individual immunological histories, so that a generalized interpretation of the determined frequencies of specific B cells in EBV-transformed tonsillar B cell populations from four donors obtained in the present study is premature (Table 1). At present we do not know whether the comparatively high frequencies of specific B cells for SRBC or PC in the EBV-transformed B cell populations stand for primary or memory cells. In this context, it may be of interest to compare the frequencies of specific B cells determined in the present study with those determined in EBV-transformed UCBL populations (in progress). On the other hand, the present system may be particularly useful to analyse quantitatively and functionally $\mathrm{B}$ cell clones specific for clinically important antigens such as autoantigens, viral antigens, etc. in normal and various diseased states (Yoshie et al. 1981). Such studies may bring about new understandings in the human immune system in both normal and diseased states.

\section{Acknowledgments}

We wish to express deep gratitudes to Prof. N. Ishida for his constant encouragement and advice and to Mr. K. Tada for his excellent technical assistance. This work was supported in part by Grants-in-Aid from The Ministry of Education, Science and Culture, Japan.

\section{References}

1) Andersson, J., Coutinho, A. \& Melchers, F. (1977) Frequencies of mitogen-reactive B cells in the mouse. II. Frequencies of B cells producing antibodies which lyse sheep or horse erythrocytes, and trinitrophenylated or nitrodiodophenylated sheep erythrocytes. J. exp. Med., 145, 1520-1530.

2) Chesebro, B. \& Metzgar, H. (1972) Affinity labeling of a phosphorylcholine binding mouse myeloma protein. Biochemistry, 11, 766-771. 
3) Eichman, K., Coutinho, A. \& Melchers, F. (1977) Absolute frequencies of lipopolysaccharide-reactive B cells producing A5A idiotype in unprimed, streptococcal A carbohydrate-primed, anti-A5A idiotype-sensitized and anti-A5A idiotype-suppressed A/J mice. J. exp. Med., 146, 1436-1449.

4) Einhorn, L., Steinitz, M., Yefenof, E., Ernberg, I., Bakacs, T. \& Klein, G. (1978) Epstein-Barr virus (EBV) receptors, complement receptors, and EBV infectibility of different lymphocyte fractions of human peripheral blood. II. Epstein-Barr virus studies. Cell. Immunol., 35, 43-58.

5) Jondal, M. \& Klein, G. (1973) Surface markers on human B and T lymphocytes. II. Presence of Epstein-Barr virus receptors on B lymphocytes. J. exp. Med., 138, 13651378.

6) Katsuki, T. \& Hinuma, Y. (1975) Characteristics of cell lines derived from human leukocytes transformed by different strains of Epstein-Barr virus. Int. J. Cancer, 15, 203-210.

7) Katsuki, T., Hinuma, Y., Yamamoto, N., Abo, T. \& Kumagai, K. (1977) Identification of the target cells in human B lymphocytes for transformation by Epstein-Barr virus. Virology, 83, 287-294.

8) Kirchner, H., Tosato, G., Blaese, R.M., Broder, S. \& Magrath, I.T. (1979) Polyclonal immunglobulin secretion by human B lymphocytes exposed to Epstein-Barr virus in vitro. J. Immunol., 122, 1310-1313.

9) Kozbor, D., Steinitz, M., Klein, G., Koskimies, S. \& Makela, O. (1979) Establishment of anti-TNP antibody producing human lymphoid lines by preselection for hapten binding followed by EBV transformation. Scand. J. Immunol., 10, 187-194.

10) Miller, G. \& Lipman, M. (1973) Release of infectious Epstein-Barr virus by transformed marmoset leukocytes. Proc. nat. Acad. Sci. USA, 70, 190-194.

11) Rosen, A., Gergely, P., Jondal, M., Klein, G. \& Britton, S. (1977) Polyclonal Ig production after Epstein-Barr virus infection of human lymphocytes in vitro. Nature, 267, 52-54.

12) Sigal, N.H. \& Klinman, N.R. (1978) The B-cell clonotype repertoire. Advanc. Immunol., 26, 255-337.

13) Steel, C.M., Philipson, J., Arthur, E., Gardiner, S., Newton, M. \& McIntosh, R.V. (1977) Possibility of EB virus preferentially transforming a subpopulation of human B lymphocytes. Nature, 270, 729-731.

14) Steinitz, M., Klein, G., Koshimies, S. \& Makel, O. (1977) EB virus-induced B lymphocyte cell lines producing specific antibody. Nature, 269, 420-422.

15) Steinitz, M., Koskimies, S., Klein, G. \& Makela, O. (1979a) Establishment of specific antibody producing human lines by antigen preselection and Epstein-Barr virus (EBV)transformation. J. clin. Lab. Immunol., 2, 1-7.

16) Steinitz, M., Seppala, I., Eichman, K. \& Klein, G. (1979b) Establishment of a human lymphoblastoid cell line with specific antibody production against group A streptococcal carbohydrate. Immunobiology, 156, 41-47.

17) Tsuchiya, S., Yokoyama, S., Yoshie, O. \& Ono, Y. (1980) Production of diphtheria antitoxin antibody in Epstein-Barr virus induced lymphoblastoid cell lines. $J$. Immunol., 124, 1970-1976.

18) Yoshie, O. \& Ono, Y. (1980) Anti-phosphorylcholine antibody-producing cells in human lymphoblastoid cell lines established by transformation with Epstein-Barr virus. Cell. Immunol., 56, 305-316.

19) Yoshie, O., Tada, K. \& Ono, Y. (1980) Immunoglobulin production in Epstein-Barr virus-induced human monoclonal lymphoblastoid cell lines. Tohoku J. exp. Med., 132, 397-403.

20) Yoshie, O., Kanamori, T. \& Ono, Y. (1981) Quantitative analyses of specific B cells for sheep red blood cell, phosphorylcholine and hepatitis B surface antigen in human B cell populations by polyclonal transformation with Epstein-Barr virus. Tohoku J. exp. Med., 134, 115-123. 
21) Zurawski, V.R., Jr., Haber, E. \& Black, P.H. (1978) Production of antibody to tetanus toxoid by continuous human lymphoblastoid cell lines. Science, 199, 14391441 . 